\title{
Anatomia do lenho de oito espécies de lianas da família Leguminosae ocorrentes na Floresta Atlântica
}

\author{
Arno Fritz das Neves Brandes ${ }^{1,2}$ e Cláudia Franca Barros ${ }^{1}$
}

Recebido em 14/02/2007. Aceito em 5/07/2007

\begin{abstract}
RESUMO - (Anatomia do lenho de oito espécies de lianas da família Leguminosae ocorrentes na Floresta Atlântica). Lianas são importantes componentes estruturais das florestas tropicais, apesar disso a anatomia destes vegetais é pouco estudada. A família Leguminosae é relatada como a segunda maior em número de espécies de lianas, contudo pouco se conhece da diversidade anatômica das lianas desta família. O presente estudo descreveu e analisou a anatomia do lenho de oito espécies de lianas da família Leguminosae, ocorrentes no Parque Nacional do Itatiaia, localizado no Estado do Rio de Janeiro, região Sudeste do Brasil, local inserido no bioma Floresta Atlântica. As espécies apresentaram características comuns ao hábito liana, como: elementos de vaso com diâmetro elevado, com duas categorias de diâmetro; e maior proporção de parênquima axial em comparação às fibras. Quatro espécies do gênero Senegalia apresentaram variações cambiais produzidas por um único câmbio, normal em produto mas anormal em conformação. A anatomia do lenho das espécies estudadas é muito semelhante por compartilharem o mesmo hábito e pertencerem à mesma família. Apesar disso, as oito espécies estudadas puderam ser diferenciadas. As espécies com variações cambiais e Dalbergia frutescens são facilmente diferenciadas das demais. Contudo Senegalia tenuifolia, Piptadenia micracantha e Piptadenia adiantoides necessitam ser examinadas com muita cautela para identificá-las exclusivamente pela anatomia do lenho.
\end{abstract}

Palavras-chave: anatomia da madeira, lianas, Mata Atlântica, Leguminosae

\begin{abstract}
Wood anatomy of eight liana species of Leguminosae family from Atlantic Rain Forest). Lianas are important structural component of tropical forests and even though the anatomy of these plants is poorly studied. Leguminosae family is reported as the second larger family in number of liana species, but little is know about the anatomical diversity of lianas from this family. The present study described and analyzed the wood anatomy of eight liana species of Leguminosae family, from Parque Nacional do Itatiaia, located in Rio de Janeiro State, Southeast region of Brazil and included in Atlantic Rain Forest Biome. The species show common features with the liana habit, as: wide vessels, vessel dimorphism, and high proportion of parenchyma when compared with fibers. Four species of Senegalia genus showed cambial variants made by a single cambium, normal in products but abnormal in conformation. The studied species have similar wood anatomy, many of which are because they belong to the same family and share the same habit. Nevertheless, the eight species studied could be distinguished. The species with cambial variants and Dalbergia frutescens are easy distinguished from the others. However Senegalia tenuifolia, Piptadenia micracantha and Piptadenia adiantoides require much wariness examination to identify the species exclusively by wood anatomical features.
\end{abstract}

Key words: wood anatomy, lianas, Atlantic Rain Forest, Leguminosae

\section{Introdução}

Lianas são trepadeiras lenhosas que iniciam seu desenvolvimento no solo e com o crescimento perdem sua habilidade de se sustentar, necessitando de suporte para ascender à copa (Gentry 1991; Gerwing et al. 2006). Nas florestas tropicais as lianas têm grande representatividade na riqueza e abundância de espécies (Putz \& Money 1991; Schnitzer \& Bongers 2002). Apesar de serem muito importantes nos ecossistemas tropicais sua anatomia e biologia são pouco estudadas (Carlquist 1985; Ewers \& Fisher 1991; Bamber \& Ter Welle 1994).

A anatomia do caule das lianas é muito peculiar, geralmente exibe características relacionadas ao hábito trepador como a presença de variações cambiais, elementos de vaso de grande diâmetro, dimorfismo dos vasos, grande quantidade de parênquima e pequena proporção de fibras (Carlquist 1991; Bamber \& Ter Welle 1994). As lianas têm caules finos em relação à

\footnotetext{
1 Instituto de Pesquisas Jardim Botânico do Rio de Janeiro, Programa Mata Atlântica, Rua Pacheco Leão 915, Jardim Botânico, 22460-030 Rio de Janeiro, RJ, Brasil

2 Autor para correspondência: arnofnb@jbrj.gov.br
} 
área foliar, possivelmente devido à reduzida demanda mecânica, visto que utiliza outros suportes para a sustentação (Ewers \& Fisher 1991; Ewers et al. 1991). Em seus finos caules estão presentes vasos largos que conferem grande eficiência na condução (Ewers et al. 1991; Bamber \& Ter Welle 1994), e muitas vezes, simultaneamente, vasos pequenos que conferem segurança na condução (Carlquist 1975).

A família Leguminosae é uma das mais representativas em número de espécies de lianas na região tropical (Gentry 1991), fato comprovado em levantamentos realizados na Floresta Atlântica (Resende \& Ranga 2005). A literatura relaciona estudos sobre a anatomia de lianas da família Leguminosae (Ewers \& Fisher 1991; Vieira 1994), contudo o número de trabalhos ainda é pequeno quando comparado ao número total de espécies de lianas.

Neste trabalho foi realizado o estudo e a caracterização anatômica de oito espécies de lianas da família Leguminosae, num remanescente de Floresta Atlântica da região sudeste do Brasil (Parque Nacional do Itatiaia). Algumas das questões que vamos elucidar são: As características anatômicas do lenho destas espécies seguem as tendências anatômicas das lianas? Correspondem às características atribuídas para a família Leguminosae? Pela anatomia do lenho é possível diferenciar estas espécies?

\section{Material e métodos}

As coletas foram realizadas no Parque Nacional do Itatiaia, município de Itatiaia, Estado do Rio de Janeiro, sudeste do Brasil. Localizado entre as coordenadas geográficas $22^{\circ} 19^{\prime} \mathrm{S}$ e $22^{\circ} 45^{\prime} \mathrm{S}, 44^{\circ} 15^{\prime} \mathrm{W}$ e 4450'W, possui área de 30.000,00 ha (Ibama 2006). A vegetação é do tipo Floresta Atlântica stricto senso (Oliveira Filho \& Fontes 2000). Na região ocorre o predomínio de relevo montanhoso com bem delimitados cinturões climáticos e de vegetação relacionados com o gradiente altitudinal. As coletas foram realizadas entre $700 \mathrm{~m}$ e $1.100 \mathrm{~m}$ de altitude, onde apresenta média anual de precipitação de $1.699 \mathrm{~mm}$ e média anual de temperatura de $18,2{ }^{\circ} \mathrm{C}$. O clima é temperado úmido, tipo $C f b$ pelo sistema de Köppen's (Segadas-Vianna \& Dau 1965).

Oito espécies de lianas pertencentes à família Leguminosae e às subfamílias Mimosoideae e Papilionoideae, foram coletadas (Tab. 1). Foram selecionadas lianas com diâmetro do caule maior do que $2,0 \mathrm{~cm}$ a aproximadamente $1,3 \mathrm{~m}$ acima do solo, sem injúrias e deformidades, região onde foi removida a amostra do lenho. De cada indivíduo amostrado, foi coletado um testemunho com estruturas reprodutivas e/ou vegetativas, que foi depositado na coleção do Herbário do Jardim Botânico do Rio de Janeiro (RB). Foram registradas as coordenadas geográficas do local de coleta e a altitude com aparelho GPS Garmin.

Para a microscopia óptica, os corpos de prova foram amolecidos, seccionados no micrótomo de deslize Spencer 860 com espessura entre 16 a $30 \mu \mathrm{m}$ (Ceccantini 1997). Em seguida, foram clarificados, corados com safranina e azul de astra (Bukatsch 1972), desidratados (Johansen 1940; Sass 1958) e montados com resina sintética. Para a descrição e mensuração os elementos celulares foram dissociados utilizandose a solução de Franklin (Jane 1956). Os macerados foram corados com Safranina aquosa $1 \%$ e montados em lâminas semi-permanentes com glicerina $50 \%$ (Strasburger 1924). Cortes histológicos foram corados com lugol para observação de amido (Johansen 1940).

As lâminas obtidas foram observadas ao microscópio Olympus BX50 e as imagens capturadas com o software Image Pro Plus versão 3.0 para Windows, ligado ao microscópio através de uma câmera de vídeo Media Cybernetics CoolSNAP-Pro, estrutura usada para proceder às medidas e contagens. Os cristais de oxalato de cálcio foram observados com microscópio de luz polarizada Zeiss com filtro vermelho $\lambda$.

As amostras de madeira e as lâminas permanentes foram incorporadas ao acervo da Xiloteca do Jardim Botânico do Rio de Janeiro (RBw).

A terminologia utilizada nas descrições, assim como as contagens e as mensurações seguem recomendações do IAWA Committee (1989). As variações cambiais foram referidas seguindo Carlquist (2001). Para o cálculo da porcentagem de vasos, parênquima axial, parênquima radial e fibras em relação ao tecido xilemático, utilizou-se uma grade sobreposta às imagens capturadas do plano transversal, onde foram considerados trinta pontos formados pela interseção das linhas da grade que se distanciavam em $100 \mu \mathrm{m}$. Foram observadas dez imagens por indivíduo e calculou-se a porcentagem de cada imagem observada.

Com os dados quantitativos, foram realizadas análises estatísticas descritivas para a caracterização e comparação das espécies. Também foram realizadas análises de inferência estatística como a análise de distribuição amostral e testes de normalidade de Kolmogorov-Smirnov. Foi utilizada a análise de fatores pelo método de componentes principais (PCA) na definição das características que mais influenciaram 
Tabela 1. Dados quantitativos das espécies estudadas. Para cada característica é apresentada mínima (mín), média (méd), máxima (máx) e desvio padrão (d.p.).

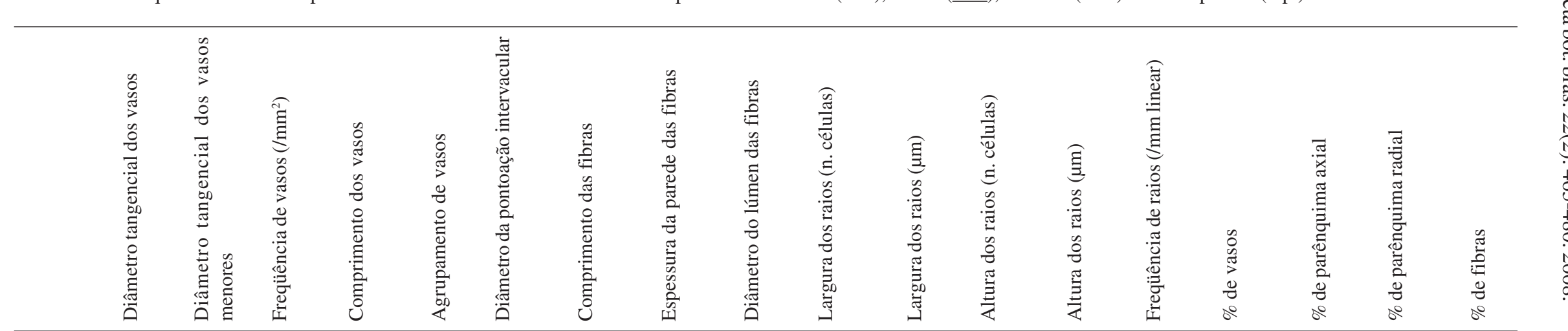

Senegalia grandistipula (Benth.) Seigler \& Ebinger

\begin{tabular}{|c|c|c|c|c|c|c|c|c|c|c|c|c|c|c|c|c|c|c|}
\hline mím & 75,30 & 16,26 & 6 & 147,41 & 1 & 5,59 & 407,20 & 3,20 & 3,98 & 1 & 11,49 & 3 & 50,78 & 3 & 20 & 17 & 3 & 7 \\
\hline méd & $\underline{196,32}$ & $\underline{37,23}$ & $\underline{14}$ & $\underline{409,94}$ & $\underline{3}$ & $\underline{7,31}$ & $\underline{1021,82}$ & $\underline{5,11}$ & $\underline{7,61}$ & $\underline{2}$ & $\underline{25,62}$ & $\underline{16}$ & $\underline{284,01}$ & $\underline{6}$ & $\underline{32}$ & $\underline{35}$ & $\underline{12}$ & $\underline{21}$ \\
\hline máx & 330,79 & 108,34 & 44 & 727,02 & 21 & 9,88 & 1786,20 & 7,50 & 13,20 & 6 & 50,63 & 54 & 1068,33 & 9 & 57 & 53 & 23 & 53 \\
\hline d.p. & 54,82 & 17,27 & 9 & 112,05 & 4 & 0,93 & 314,41 & 1,02 & 2,48 & 1 & 9,26 & 11 & 214,24 & 2 & 8 & 9 & 6 & 11 \\
\hline \multicolumn{19}{|c|}{ Senegalia lacerans (Benth.) Seigler \& Ebinger } \\
\hline mím & 41,63 & 11,49 & 6 & 172,29 & 1 & 4,88 & 443,27 & 2,78 & 2,51 & 1 & 9,20 & 2 & 43,74 & 2 & 3 & 19 & 0 & 12 \\
\hline méd & $\underline{174,12}$ & $\underline{27,18}$ & $\underline{25}$ & $\underline{389,62}$ & $\underline{5}$ & $\underline{7,40}$ & $\underline{1151,29}$ & $\underline{5,31}$ & $\underline{6,47}$ & $\underline{3}$ & $\underline{34,79}$ & $\underline{23}$ & $\underline{304,21}$ & $\underline{5}$ & $\underline{29}$ & $\underline{33}$ & $\underline{12}$ & $\underline{26}$ \\
\hline máx & 328,45 & 56,23 & 98 & 539,77 & 74 & 12,33 & 1930,55 & 8,67 & 14,11 & 10 & 103,68 & 94 & 1045,81 & 9 & 47 & 60 & 21 & 46 \\
\hline d.p. & 60,80 & 9,71 & 18 & 79,02 & 10 & 1,37 & 275,70 & 1,13 & 2,31 & 2 & 18,00 & 17 & 206,17 & 1 & 8 & 9 & 5 & 9 \\
\hline \multicolumn{19}{|c|}{ Senegalia martiusiana (Steud.) Seigler \& Ebinger } \\
\hline mím & 80,46 & 11,72 & 7 & 178,93 & 1 & 4,89 & 405,13 & 2,23 & 1,92 & 1 & 7,57 & 2 & 43,68 & 2 & 23 & 17 & 3 & 0 \\
\hline méd & $\underline{235,93}$ & $\underline{32,23}$ & $\underline{19}$ & $\underline{418,43}$ & $\underline{3}$ & $\underline{7,67}$ & $\underline{1009,63}$ & $\underline{5,48}$ & $\underline{6,64}$ & $\underline{2}$ & $\underline{24,01}$ & $\underline{15}$ & $\underline{202,78}$ & $\underline{5}$ & $\underline{50}$ & $\underline{32}$ & $\underline{10}$ & $\underline{8}$ \\
\hline máx & 440,96 & 96,91 & 61 & 673,88 & 26 & 11,48 & 1867,58 & 10,72 & 15,95 & 4 & 48,77 & 47 & 540,99 & 10 & 70 & 53 & 27 & 31 \\
\hline d.p. & 66,17 & 13,03 & 11 & 103,51 & 5 & 1,40 & 368,13 & 1,61 & 2,74 & 1 & 7,57 & 9 & 94,62 & 2 & 10 & 8 & 4 & \\
\hline \multicolumn{19}{|c|}{ Senegalia pedicellata (Benth.) Seigler \& Ebinger } \\
\hline mím & 66,83 & 13,40 & 17 & 178,81 & 1 & 5,13 & 484,75 & 2,05 & 2,72 & 1 & 5,58 & 2 & 25,29 & 3 & 17 & 20 & 0 & 0 \\
\hline méd & $\underline{131,19}$ & $\underline{27,65}$ & $\underline{31}$ & $\underline{393,97}$ & $\underline{3}$ & $\underline{7,68}$ & $\underline{976,12}$ & $\underline{4,61}$ & $\underline{7,18}$ & $\underline{2}$ & $\underline{18,78}$ & $\underline{11}$ & $\underline{178,85}$ & $\underline{6}$ & $\underline{38}$ & $\underline{43}$ & $\underline{8}$ & $\underline{11}$ \\
\hline máx & 287,36 & 58,20 & 70 & 605,30 & 15 & 10,91 & 1739,57 & 8,07 & 15,95 & 3 & 34,48 & 31 & 490,87 & 10 & 57 & 60 & 17 & 27 \\
\hline d.p. & 35,98 & 9,27 & 10 & 97,32 & 3 & 1,15 & 284,91 & 1,15 & 2,55 & 1 & 6,01 & 6 & 91,93 & 2 & 9 & 8 & 4 & 7 \\
\hline \multicolumn{19}{|c|}{ Senegalia tenuifolia (L.) Britton \& Rose } \\
\hline mím & 81,24 & 11,49 & 6 & 225,47 & 1 & 5,11 & 570,94 & 3,02 & 2,72 & 1 & 9,48 & 4 & 57,65 & 3 & 12 & 20 & 7 & 3 \\
\hline méd & $\underline{189,19}$ & $\underline{33,84}$ & $\underline{13}$ & $\underline{405,32}$ & $\underline{4}$ & $\underline{7,14}$ & $\underline{1193,24}$ & $\underline{5,07}$ & $\underline{5,33}$ & $\underline{4}$ & $\underline{45,24}$ & $\underline{60}$ & $\underline{713,10}$ & $\underline{5}$ & $\underline{33}$ & $\underline{32}$ & $\underline{14}$ & $\underline{21}$ \\
\hline máx & 361,33 & 74,77 & 35 & 615,90 & 26 & 9,54 & 2491,97 & 6,91 & 9,79 & 8 & 73,60 & 277 & 3258,75 & 9 & 57 & 41 & 23 & 39 \\
\hline d.p. & 67,17 & 14,46 & 7 & 110,54 & 6 & 0,97 & 376,76 & 1,06 & 1,59 & 2 & 14,64 & 62 & 627,66 & 2 & 15 & 6 & 4 & 11 \\
\hline
\end{tabular}


Piptadenia adiantoides (Spreng.) J.F. Macbr.

\begin{tabular}{|c|c|c|c|c|c|c|c|c|c|c|c|c|c|c|c|c|c|c|}
\hline mím & 95,62 & 13,00 & 2 & 240,34 & 1 & 5,81 & 460,18 & 2,36 & 2,95 & 1 & 13,79 & 2 & 67,30 & 3 & 10 & 10 & 7 & 5 \\
\hline méd & $\underline{272,51}$ & $\underline{48,78}$ & $\underline{12}$ & $\underline{416,89}$ & $\underline{4}$ & $\underline{8,34}$ & 957,71 & $\underline{4,67}$ & $\underline{8,72}$ & $\underline{3}$ & $\underline{44,44}$ & $\underline{25}$ & $\underline{419,10}$ & $\underline{7}$ & $\underline{38}$ & $\underline{24}$ & $\underline{17}$ & $\underline{22}$ \\
\hline máx & 480,28 & 144,75 & 42 & 653,86 & 33 & 12,38 & 1433,00 & 8,38 & 16,89 & 7 & 95,26 & 113 & 1365,41 & 12 & 57 & 42 & 26 & 53 \\
\hline d.p. & 78,89 & 30,40 & 9 & 85,45 & 6 & 1,06 & 224,01 & 1,16 & 3,21 & 1 & 17,10 & 19 & 253,73 & 2 & 12 & 9 & 4 & 12 \\
\hline \multicolumn{19}{|c|}{ Piptadenia micracantha Benth. } \\
\hline mím & 69,16 & 13,40 & 2 & 154,04 & 1 & 6,30 & 535,57 & 2,96 & 2,72 & 1 & 16,09 & 3 & 48,28 & 1 & 7 & 10 & 7 & 7 \\
\hline méd & $\underline{300,36}$ & $\underline{57,37}$ & $\underline{11}$ & $\underline{435,16}$ & $\underline{4}$ & $\underline{9,76}$ & $\underline{1019,71}$ & $\underline{5,64}$ & $\underline{6,54}$ & $\underline{4}$ & $\underline{51,24}$ & $\underline{31}$ & $\underline{461,41}$ & $\underline{5}$ & $\underline{34}$ & $\underline{26}$ & $\underline{15}$ & $\underline{25}$ \\
\hline máx & 543,43 & 154,30 & 32 & 881,95 & 47 & 14,02 & 1517,20 & 9,38 & 13,84 & 10 & 121,32 & 117 & 1627,59 & 10 & 67 & 47 & 24 & 47 \\
\hline d.p. & 99,41 & 30,21 & 8 & 111,18 & 7 & 1,38 & 201,25 & 1,24 & 2,20 & 2 & 18,19 & 26 & 345,53 & 2 & 11 & 7 & 4 & 11 \\
\hline \multicolumn{19}{|c|}{ Dalbergia frutescens (Vell.) Britton var. frutescens } \\
\hline mím & 16,09 & & 3 & 98,48 & 1 & 5,81 & 452,38 & 2,62 & 3,36 & 1 & 9,20 & 3 & 52,30 & 3 & 0 & 18 & 0 & 11 \\
\hline méd & $\underline{102,50}$ & & $\underline{10}$ & $\underline{201,62}$ & $\underline{2}$ & $\underline{8,86}$ & $\underline{927,79}$ & $\underline{4,56}$ & $\underline{9,71}$ & $\underline{2}$ & $\underline{25,69}$ & $\underline{9}$ & $\underline{156,09}$ & $\underline{8}$ & $\underline{15}$ & $\underline{33}$ & $\underline{12}$ & $\underline{40}$ \\
\hline máx & 360,95 & & 21 & 260,22 & 12 & 15,61 & 1381,08 & 6,65 & 19,85 & 3 & 50,63 & 20 & 312,65 & 13 & 47 & 57 & 21 & 68 \\
\hline d.p. & 72,56 & & 5 & 25,60 & 2 & 1,51 & 178,38 & 0,87 & 3,12 & 0 & 8,54 & 3 & 42,43 & 2 & 9 & 9 & 4 & 13 \\
\hline
\end{tabular}

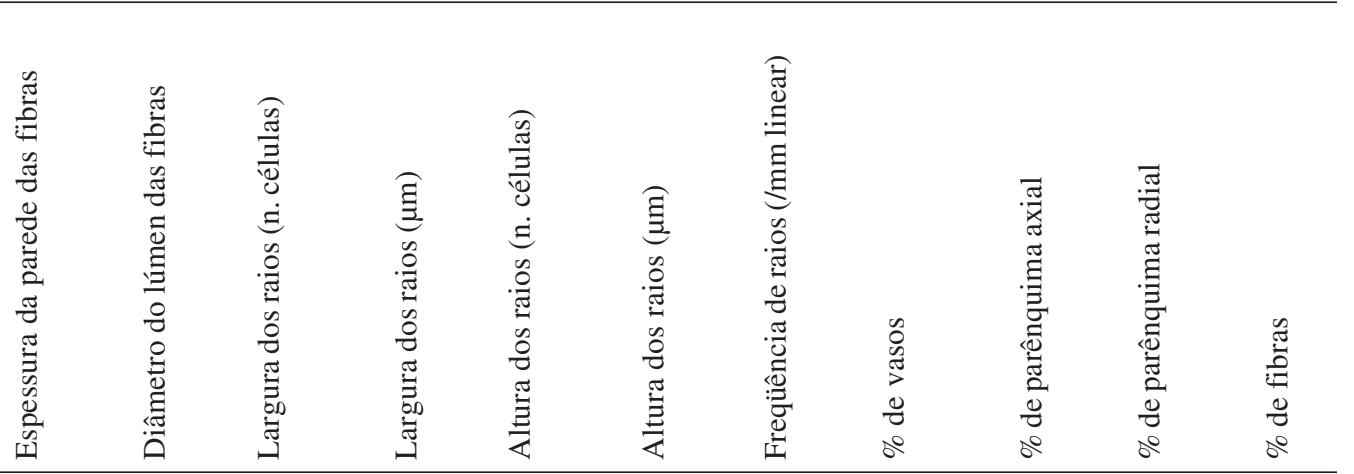


na diferenciação das espécies, influenciando no modelo espacial produzido (Manly 1994). A análise de fatores foi realizada com 14 variáveis de um total de 47 variáveis. Estas 14 variáveis são: camadas de crescimento distintas, anel semi-poroso, fibras septadas, parênquima axial vasicêntrico, parênquima axial aliforme, parênquima axial marginal, parênquima axial difuso, estratificação, variação cambial presente, diâmetro tangencial dos vasos, freqüência de vasos por milímetro linear, comprimento dos vasos, largura do raio em micrômetros, altura do raio em micrômetros. As demais variáveis foram excluídas da análise por não apresentarem variação ou por apresentarem o valor dos fatores muito baixo. Com os dados qualitativos, foi realizada a análise de agrupamento através de distâncias de Manhattan (Manhattan distances, Unweighted pair-group average) (Manly 1994). Foram realizadas analises de variância (ANOVA) para testar se existem diferenças significativas nas médias de algumas características quantitativas entre algumas espécies. Todas as análises foram realizadas no programa Statistic 6.0 para Windows.

\section{Resultados}

Senegalia grandistipula (Benth.) Seigler \& Ebinger Fig. 1, 9

Camadas de crescimento: distintas a indistintas, de ocorrência esporádica, delimitadas por anel semiporoso, zona fibrosa, achatamento radial de células no lenho tardio, máculas e canais traumáticos.

Elementos de vaso: porosidade difusa, mas pode apresentar anel semi-poroso esporadicamente; solitários e múltiplos de 2 a 21 vasos em cadeias radiais e cachos (1-3-21); placas de perfuração simples; pontoações intervasculares alternas guarnecidas pequenas a médias, com 5,59-7,31-9,88 $\mu \mathrm{m}$; pontoações raiovasculares com bordas distintas; vasos com duas classes de diâmetro; diâmetro tangencial dos maiores 75,30-196,32-330,79 $\mu \mathrm{m}$; diâmetro tangencial dos menores 16,26-37,23-108,34 $\mu \mathrm{m}$; freqüência de 6-14-44 / $\mathrm{mm}^{2}$; comprimento 147,41-409,94-727,02 $\mu \mathrm{m}$; obstruções por tilos e substâncias que coram em vermelho e azul com safranina e azul de astra nos maiores e menores; representam 20-32-57\% do tecido xilemático.

Fibras: pontoações simples; com espessamento helicoidal; septadas e não septadas; presença de fibras gelatinosas; paredes finas a espessas, espessura da parede 3,20-5,11-7,50 $\mu \mathrm{m}$; comprimento 407,20-1021,82-
1786,20 $\mu$ m; representam 7-21-53\% do tecido xilemático.

Parênquima axial: paratraqueal vasicêntrico, aliforme e confluente; com 2 a 4 células por séries parenquimáticas; representam $17-35-53 \%$ do tecido xilemático.

Raios: uniseriados e multiseriados, largura de 1-2-6 células e 11,49-25,62-50,63 $\mu \mathrm{m}$; altura de 3-16-54 células e 50,78-284,01-1068,33 $\mu \mathrm{m}$; com frequiência de 3-6-9 /mm'; composto exclusivamente por células procumbentes; representam 3-12-23\% do tecido xilemático.

Máculas e canais traumáticos: presentes.

Variação cambial: caule lobado conferindo aspecto quadrangular.

Inclusões minerais: presença de cristais prismáticos de oxalato de cálcio em séries parenquimáticas axiais com 1 cristal por câmara, chegando a mais de 30 na série.

Amido: presente em fibras e no parênquima axial. Material examinado: RBw 8643, 8644.

\section{Senegalia lacerans (Benth.) Seigler \& Ebinger}

Fig. 2, 10

Camadas de crescimento: distintas a indistintas, de ocorrência esporádica, delimitadas por anel semiporoso, parênquima marginal, zona fibrosa, achatamento radial de células no lenho tardio, máculas e canais traumáticos.

Elementos de vaso: porosidade difusa, mas pode apresentar anel semi-poroso esporadicamente; solitários e múltiplos de 2 a 74 vasos em cadeias radiais e cachos (1-5-74); placas de perfuração simples; pontoações intervasculares alternas guarnecidas pequenas a grandes, com 4,88-7,40-12,33 $\mu \mathrm{m}$; pontoações raiovasculares com bordas distintas; vasos de duas classes de diâmetro; diâmetro tangencial dos maiores 41,63-174,12-328,45 $\mu \mathrm{m}$; diâmetro tangencial dos menores 11,49-27,18-56,23 um; freqüência de 6-25-98 / $/ \mathrm{mm}^{2}$; comprimento 172,29-389,62-539,77 $\mu \mathrm{m}$; obstruções por tilos e substâncias que coram em vermelho e azul com safranina e azul de astra nos maiores e menores; representam 3-29-47\% do tecido xilemático.

Fibras: pontoações simples; com espessamento helicoidal; septadas e não septadas; presença de fibras gelatinosas; paredes finas; espessura da parede 2,785,31-8,67 mm; comprimento 443,27-1151,29-1930,55 $\mathrm{mm}$; representam 12-26-46\% do tecido xilemático.

Parênquima axial: paratraqueal aliforme e confluente formando faixas; células fusiformes e formando séries com 2 a 5 células; representam 


\section{9-33-60\% do tecido xilemático.}

Raios: uniseriados e multiseriados, largura de 1-310 células e 9,20-34,79-103,68 $\mu \mathrm{m}$; altura de 2-23-94 células e 43,74-304,21-1045,81 $\mu$ m; com freqüência de 2-5-9 /mm'; composto exclusivamente por células procumbentes; representam $0-12-21 \%$ do tecido xilemático.

Máculas e canais traumáticos: presentes.

Variação cambial: xilema fissurado.

Inclusões minerais: presença de cristais prismáticos de oxalato de cálcio em séries parenquimáticas axiais com 1 cristal por câmara, chegando a mais de 30 na série.

Amido: presente em fibras e no parênquima axial.

Material examinado: RBw 8607, 8608, 8624, 8625, $8631,8641,8642$.

\section{Senegalia martiusiana (Steud.) Seigler \& Ebinger}

Fig. 3, 11

Camadas de crescimento: distintas a indistintas, de ocorrência esporádica, delimitadas por anel semiporoso, zona fibrosa, máculas e canais traumáticos.

Elementos de vaso: porosidade difusa mas pode apresentar anel semi-poroso esporadicamente; solitários e múltiplos de 2 a 26 vasos em cadeias radiais e cachos (1-3-26); placas de perfuração simples; pontoações intervasculares alternas guarnecidas pequenas a grandes, com 4,89-7,67-11,48 $\mu \mathrm{m}$; pontoações raiovasculares com bordas distintas; vasos de duas classes de diâmetro; diâmetro tangencial dos maiores 80,46-235,93-440,96 $\mu \mathrm{m}$; diâmetro tangencial dos menores 11,72-32,23-96,91 $\mu \mathrm{m}$; freqüência de $7-19-61 / \mathrm{mm}^{2}$; comprimento de 178,93-418,43-673,88 $\mu$ m; obstruções por tilos e substâncias que coram em vermelho e azul com safranina e azul de astra nos maiores e menores; representam 23-50-70\% do tecido xilemático.

Fibras: pontoações simples; com espessamento helicoidal; septadas e não septadas; presença de fibras gelatinosas; paredes finas a espessas; espessura da parede 2,23-5,48-10,72 $\mu \mathrm{m}$; comprimento 405,131009,63-1867,58 $\mu \mathrm{m}$; representam 0-8-31\% do tecido xilemático.

Parênquima axial: paratraqueal confluente; células fusiformes e formando séries com 2 a 4 células; representam 17-32-53\% do tecido xilemático.

Raios: uniseriados e multiseriados, largura de 1-24 células e 7,57-24,01-48,77 $\mu \mathrm{m}$; altura de 2-15-47 células e 43,68-202,78-540,99 $\mu \mathrm{m}$; com freqüência de 2-5-10/mm'; composto exclusivamente por células procumbentes; representam 3-10-27\% do tecido xilemático.
Máculas e canais traumáticos: presentes.

Variação cambial: caule lobado com lobos cilíndricos.

Inclusões minerais: presença de cristais prismáticos de oxalato de cálcio em séries parenquimáticas axiais com 1 cristal por câmara, chegando a mais de 30 na série.

Amido: presente em fibras e no parênquima axial.

Material examinado: RBw 8653, 8655, 8656, 8657, 8660,8661 .

\section{Senegalia pedicellata (Benth.) Seigler \& Ebinger}

Fig. 4, 12

Camadas de crescimento: distintas a indistintas, de ocorrência esporádica, delimitadas por máculas, canais traumáticos, anel semi-poroso e zona fibrosa.

Elementos de vaso: porosidade difusa mas pode apresentar anel semi-poroso esporadicamente; solitários e múltiplos de 2 a 15 vasos em cadeias radiais e cachos (1-3-15); placas de perfuração simples; pontoações intervasculares alternas guarnecidas pequenas a médias, com 5,13-7,68-10,91 $\mu \mathrm{m}$; pontoações raiovasculares com bordas distintas; vasos de duas classes de diâmetro; diâmetro tangencial dos maiores 66,83-131,19-287,36 $\mu$ m; diâmetro tangencial dos menores 13,40-27,65-58,20 mm; freqüência de 17-

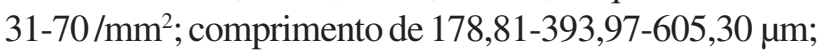
obstruções por tilos e substâncias que coram em vermelho e azul com safranina e azul de astra nos maiores e menores; representam 17-38-57\% do tecido xilemático.

Fibras: pontoações simples; com espessamento helicoidal; septadas e não septadas; presença de fibras gelatinosas; paredes finas a espessas; espessura da parede 2,05-4,61-8,07 $\mu \mathrm{m}$; comprimento 484,75-976,12$1739,57 \mu \mathrm{m}$; representam $0-11-27 \%$ do tecido xilemático.

Parênquima axial: paratraqueal confluente; células fusiformes e formando séries com 2 a 5 células; representam 20-43-60\% do tecido xilemático.

Raios: uniseriados e multiseriados, largura de 1-23 células e 5,58-18,78-34,48 $\mu$ m; altura 2-11-31 células e 25,29-178,85-490,87 mm; com freqüência de 3-6 10/mm'; composto exclusivamente por células procumbentes; representam 0-8-17\% do tecido xilemático.

Máculas e canais traumáticos: presentes.

Variação cambial: caule lobado com lobos achatados.

Inclusões minerais: presença de cristais prismáticos de oxalato de cálcio em séries parenquimáticas 
axiais com 1 cristal por câmara, chegando a mais de 30 na série.

Amido: presente em fibras e no parênquima axial. Material examinado: RBw 8609, 8615, 8662, 8663, 8664.

\section{Senegalia tenuifolia (L.) Britton \& Rose} Fig. 5

Camadas de crescimento: distintas, delimitadas por anel semi-poroso, parênquima marginal, zona fibrosa, achatamento radial de células no lenho tardio.

Elementos de vaso: porosidade em anel semiporoso; solitários e múltiplos de 2 a 26 vasos em cadeias radiais e cachos (1-4-26); placas de perfuração simples; pontoações intervasculares alternas guarnecidas pequenas a médias 5,11-7,14-9,54 $\mu \mathrm{m}$; pontoações raiovasculares com bordas distintas; vasos de duas classes de diâmetro ; diâmetro tangencial dos
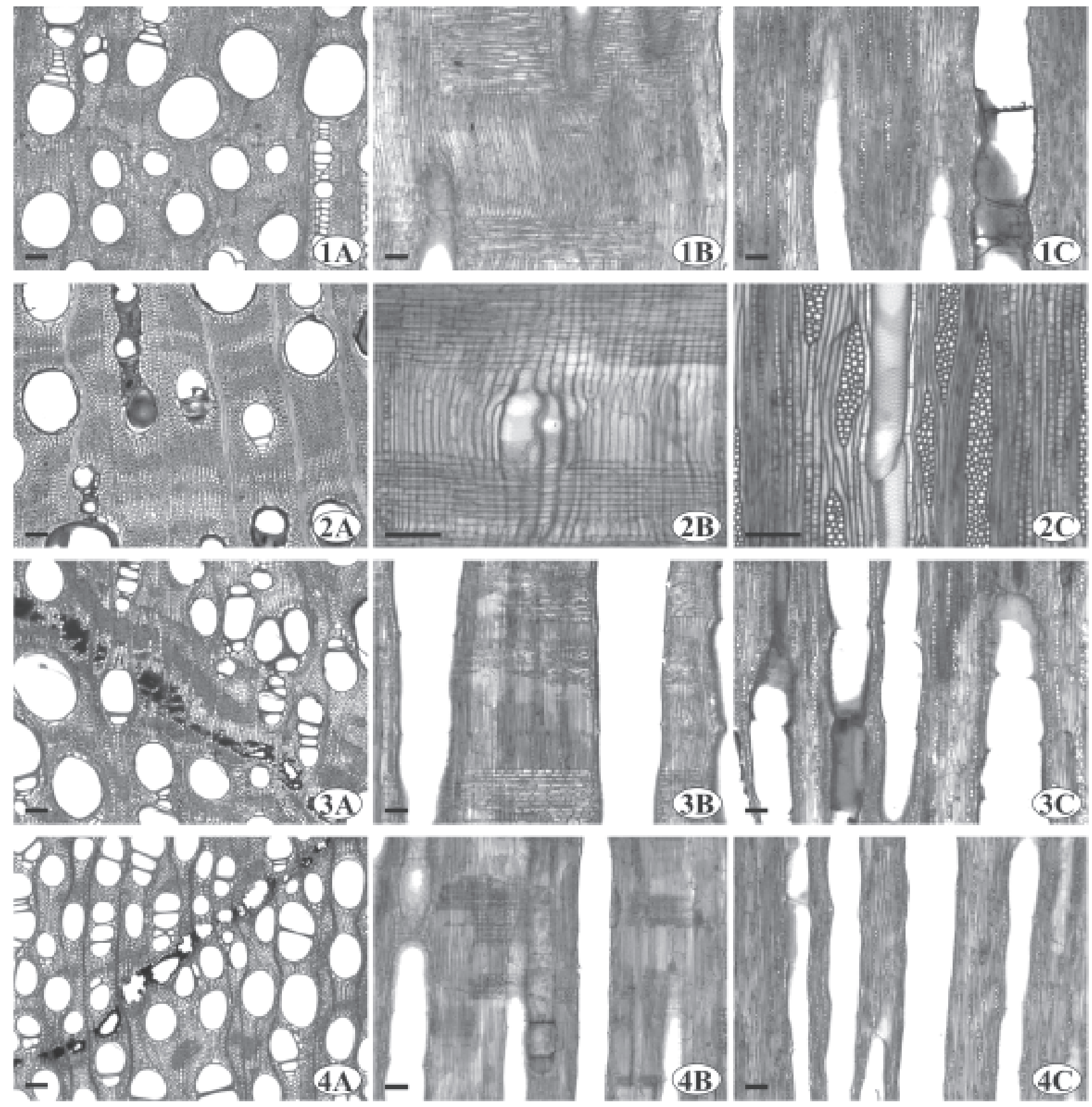

Figuras 1-4. Visão microscópica dos planos: tranversal (A), radial (B) e tangencial (C). 1. Senegalia grandistipula (Benth.) Seigler \& Ebinger. 2. Senegalia lacerans (Benth.) Seigler \& Ebinger. 3. Senegalia martiusiana (Steud.) Seigler \& Ebinger. 4. Senegalia pedicellata (Benth.) Seigler \& Ebinger. Barras $=100 \mu \mathrm{m}$. 
maiores 81,24-189,19-361,33 $\mu \mathrm{m}$; diâmetro tangencial dos menores 11,49-33,84-74,77 $\mu \mathrm{m}$; freqüência de 6-13-35 / $\mathrm{mm}^{2}$; comprimento de 225,47-405,32$615,90 \mu \mathrm{m}$; obstruções por tilos e substâncias que coram em vermelho e azul com safranina e azul de astra ; representam 12-33-57\% do tecido xilemático.

Fibras: pontoações simples; com espessamento helicoidal; septadas e não septadas; presença de fibras gelatinosas; paredes finas a espessas; espessura da parede 3,02-5,07-6,91 $\mu \mathrm{m}$; comprimento 570,941193,24-2491,97 $\mu \mathrm{m}$; representam 3-21-39\% do tecido xilemático.

Parênquima axial: paratraqueal vasicêntrico, aliforme e confluente formando faixas marginais; células fusiformes e formando séries com 2 a 4 células; representam 20-32-41\% do tecido xilemático.

Raios: uniseriados e multiseriados, largura de 1-48 células e 9,48-45,24-73,60 $\mu \mathrm{m}$; altura 4-60-277células e 57,65-713,10-3258,75 $\mu \mathrm{m}$; com freqüência de 3-5$9 / \mathrm{mm}$ '; composto exclusivamente por células procumbentes; representam $7-14-23 \%$ do tecido xilemático.

Máculas e canais traumáticos: presentes.

Inclusões minerais: presença de cristais prismáticos de oxalato de cálcio em séries parenquimáticas axiais com 1 cristal por câmara, chegando a mais de 30 na série. Cristais abundantes nos limites das camadas de crescimento.

Amido: presente no parênquima axial e raios.

Material examinado: RBw 8628, 8658.

\section{Piptadenia adiantoides (Spreng.) J.F. Macbr.}

Fig. 6

Camadas de crescimento: distintas, delimitadas por anel semi-poroso, parênquima marginal, zona fibrosa, achatamento radial de células no lenho tardio.

Elementos de vaso: porosidade em anel semiporoso; solitários e múltiplos de 2 a 33 vasos em cadeias radiais e cachos (1-4-33); placas de perfuração simples; pontoações intervasculares alternas guarnecidas pequenas a grandes 5,81-8,34-12,38 $\mu \mathrm{m}$; pontoações raiovasculares com bordas distintas; vasos de duas classes de diâmetro; diâmetro tangencial dos maiores 95,62-272,51-480,28 $\mu \mathrm{m}$; diâmetro tangencial dos menores 13,00-48,78-144,75 $\mu \mathrm{m}$; freqüência de 2-12-42 / $\mathrm{mm}^{2}$; comprimento de 240,34-416,89$653,86 \mu \mathrm{m}$; obstruções por tilos e substâncias que coram em vermelho e azul com safranina e azul de astra nos maiores e menores ; representam 10-38-57\% do tecido xilemático.
Fibras: pontoações simples; com espessamento helicoidal; não septadas e ocasionalmente septadas; presença de fibras gelatinosas; paredes finas a espessas; espessura da parede 2,36-4,67-8,38 $\mu \mathrm{m}$; comprimento 460,18-957,71-1433,00 $\mu \mathrm{m}$; representam 5-22-53\% do tecido xilemático.

Parênquima axial: paratraqueal escasso, vasicêntrico, aliforme e confluente formando faixas marginais; células fusiformes e formando séries com 2 a 4 células; representam $10-24-42 \%$ do tecido xilemático.

Raios: uniseriados e multiseriados, largura de 1-37 células e 13,79-44,44-95,26 $\mu \mathrm{m}$; altura 2-25-113 células e 67,30-419,10-1365,41 $\mu \mathrm{m}$; com freqüência de 3-7-12 /mm'; composto exclusivamente por células procumbentes; representam $7-17-26 \%$ do tecido xilemático.

Máculas e canais traumáticos: presentes.

Inclusões minerais: presença de cristais prismáticos de oxalato de cálcio em séries parenquimáticas axiais com 1 cristal por câmara, chegando a mais de 30 na série. Cristais abundantes nos limites das camadas de crescimento.

Amido: presente em fibras e no parênquima axial.

Material examinado: RBw 8635, 8636, 8646, 8648, 8652.

\section{Piptadenia micracantha Benth.}

Fig. 7

Camadas de crescimento: distintas, delimitadas por anel semi-poroso, parênquima marginal, zona fibrosa e algumas vezes por achatamento radial de células no lenho tardio.

Elementos de vaso: porosidade em anel semiporoso; solitários e múltiplos de 2 a 47 vasos em cadeias radiais e cachos (1-4-47); placas de perfuração simples; pontoações intervasculares alternas guarnecidas pequenas a grandes, com 6,30-9,76$14,02 \mu \mathrm{m}$; pontoações raiovasculares com bordas distintas; vasos de duas classes de diâmetro; diâmetro tangencial dos maiores 69,16-300,36-543,43 $\mu \mathrm{m}$; diâmetro tangencial dos menores 13,40-57,37$154,30 \mu \mathrm{m}$; frequiência de $2-11-32 / \mathrm{mm}^{2}$; comprimento de 154,04-435,16-881,95 $\mu \mathrm{m}$; obstruções por tilos e substâncias que coram em vermelho e azul com safranina e azul de astra nos maiores e menores; representam 7-34-67\% do tecido xilemático.

Fibras: pontoações simples; com espessamento helicoidal; não septadas e ocasionalmente septadas; presença de fibras gelatinosas; paredes finas a 
espessas; espessura da parede 2,96-5,64-9,38 $\mu \mathrm{m}$; comprimento 535,57-1019,71-1517,20 $\mu \mathrm{m}$; representam 7-25-47\% do tecido xilemático.

Parênquima axial: paratraqueal vasicêntrico, aliforme e confluente formando faixas marginais; células fusiformes e formando séries com 2 a 5 células; representam 10-26-47\% do tecido xilemático.

Raios: uniseriados e multiseriados, largura de 1-410 células e 16,09-51,24-121,32 $\mu \mathrm{m}$; altura 3-31-117 células e 48,28-461,41-1627,59 $\mu \mathrm{m}$; com freqüência de 1-5-10 /mm'; composto exclusivamente por células procumbentes; representam 7-15-24\% do tecido xilemático.

Inclusões minerais: presença de cristais prismáticos de oxalato de cálcio em séries parenquimáticas axiais com 1 cristal por câmara, chegando a mais de 30 na série. Cristais abundantes nos limites das camadas de crescimento.

Amido: presente em fibras e no parênquima axial.

Material examinado: RBw 8605, 8632, 8637, 8645, 8651,8654 .

Dalbergia frutescens (Vell.) Britton var. frutescens Fig. 8

Camadas de crescimento: distintas, delimitadas por anel semi-poroso, parênquima marginal, zona fibrosa, achatamento radial de células no lenho tardio.

Elementos de vaso: porosidade em anel semiporoso; solitários e múltiplos de 2 a 12 vasos em cadeias radiais e cachos (1-2-12); placas de perfuração simples; pontoações intervasculares alternas guarnecidas pequenas a grandes, com 5,81-8,86$15,61 \mu \mathrm{m}$; pontoações raiovasculares com bordas distintas; diâmetro tangencial 16,09-102,50-360,95 $\mu \mathrm{m}$; freqüência de 3-10-21 / $\mathrm{mm}^{2}$; comprimento de 98,48201,62-260,22 $\mu \mathrm{m}$; obstruções por tilos e substâncias que coram em vermelho e azul com safranina e azul de astra; representam 0-15-47\% do tecido xilemático.

Fibras: pontoações simples; com espessamento helicoidal; não septadas; presença de fibras gelatinosas; paredes finas a espessas; espessura da parede 2,62-4,56-6,65 $\mu \mathrm{m}$; comprimento 452,38-927,79$1381,08 \mu \mathrm{m}$; representam $11-40-68 \%$ do tecido xilemático.

Parênquima axial: paratraqueal aliforme, confluente formando faixas marginais, difuso e difuso em agregados, células fusiformes e formando séries com 2 células; representam 18-33-57\% do tecido xilemático.

Raios: uniseriados e multiseriados, largura de 1-23 células e 9,20-25,69-50,63 $\mu$ m; altura 3-9-20 células e 52,30-156,09-312,65 $\mu \mathrm{m}$; com freqüência de 3-8$13 / \mathrm{mm}$ '; composto exclusivamente por células procumbentes; representam $0-12-21 \%$ do tecido xilemático.

Estratificação: de raios, parênquima axial e vasos. Máculas e canais traumáticos: presentes.

Inclusões minerais: presença de cristais prismáticos de oxalato de cálcio em séries parenquimáticas axiais com 1 cristal por câmara, chegando a mais de 30 na série. Cristais abundantes nos limites das camadas de crescimento.

Amido: presente no parênquima axial e no parênquima radial.

Material examinado: RBw 8606, 8613, 8614, 8616, $8621,8622,8649$.

Todas as espécies estudadas apresentaram: elementos de vaso solitários e múltiplos em cadeias radiais e cachos; placas de perfuração simples; pontoações intervasculares alternas guarnecidas; pontoações raiovasculares com bordas distintas; obstruções por tilos e substâncias que coram em vermelho e azul com safranina e azul de astra. Fibras com pontoações simples; de paredes finas a espessas; gelatinosas; com espessamento helicoidal; e sem septos. Parênquima axial paratraqueal confluente; com células fusiformes e formando séries. Raios uniseriados e multiseriados; compostos exclusivamente por células procumbentes. Cristais prismáticos em séries parenquimáticas axiais com 1 cristal por subdivisão. Abundância de amido.

Todas as espécies pertencentes à sub-família Mimosoideae, S. grandistipula, S. lacerans, S. martiusiana, S. pedicellata, S. tenuifolia, $P$. adiantoides, $P$. micracantha, apresentaram fibras septadas, dimorfismo de vasos e amido em fibras.

Senegalia tenuifolia, $P$. adiantoides, $P$. micracantha e D. frutescens apresentaram camadas de crescimento distintas, parênquima marginal e anel semi-poroso. Somente $D$. frutescens apresentou estratificação, parênquima axial difuso e não apresentou dimorfismo de vasos. Piptadenia adiantoides apresentou parênquima axial paratraqueal escasso. Em $P$. micracantha não foram observadas máculas e canais traumáticos.

Quatro espécies do gênero Senegalia apresentaram variações cambiais produzidas a partir de um único câmbio normal em produto, mas anormal em conformação. Em S. grandistipula, S. martiusiana e $S$. pedicellata a variação cambial é do tipo caule lobado, contudo existem diferenças entre 
estas espécies (Fig. 9-12). Em S. grandistipula os lóbos conferem um formato quadrangular para o caule (Fig. 9), em S. martiusiana os lóbos são cilíndricos (Fig. 11), enquanto em S. pedicellata os lóbos são achatados (Fig. 12). S. lacerans apresenta a variação cambial do tipo xilema fissurado (Fig. 10). Nessas espécies ocorrem camadas de crescimento esporádicas e foi comum a presença de máculas e canais traumáticos.

A média e a amplitude do diâmetro dos vasos foi elevada em $P$. micracantha e $P$. adiantoides, chegando a 543,43 mm em P. micracantha. Dalbergia frutescens, em contraposição, tem a menor média e do diâmetro dos vasos. Piptadenia micracantha apresentou as maiores pontoações intervasculares. As espécies $S$. martiusiana e $S$. lacerans apresentaram
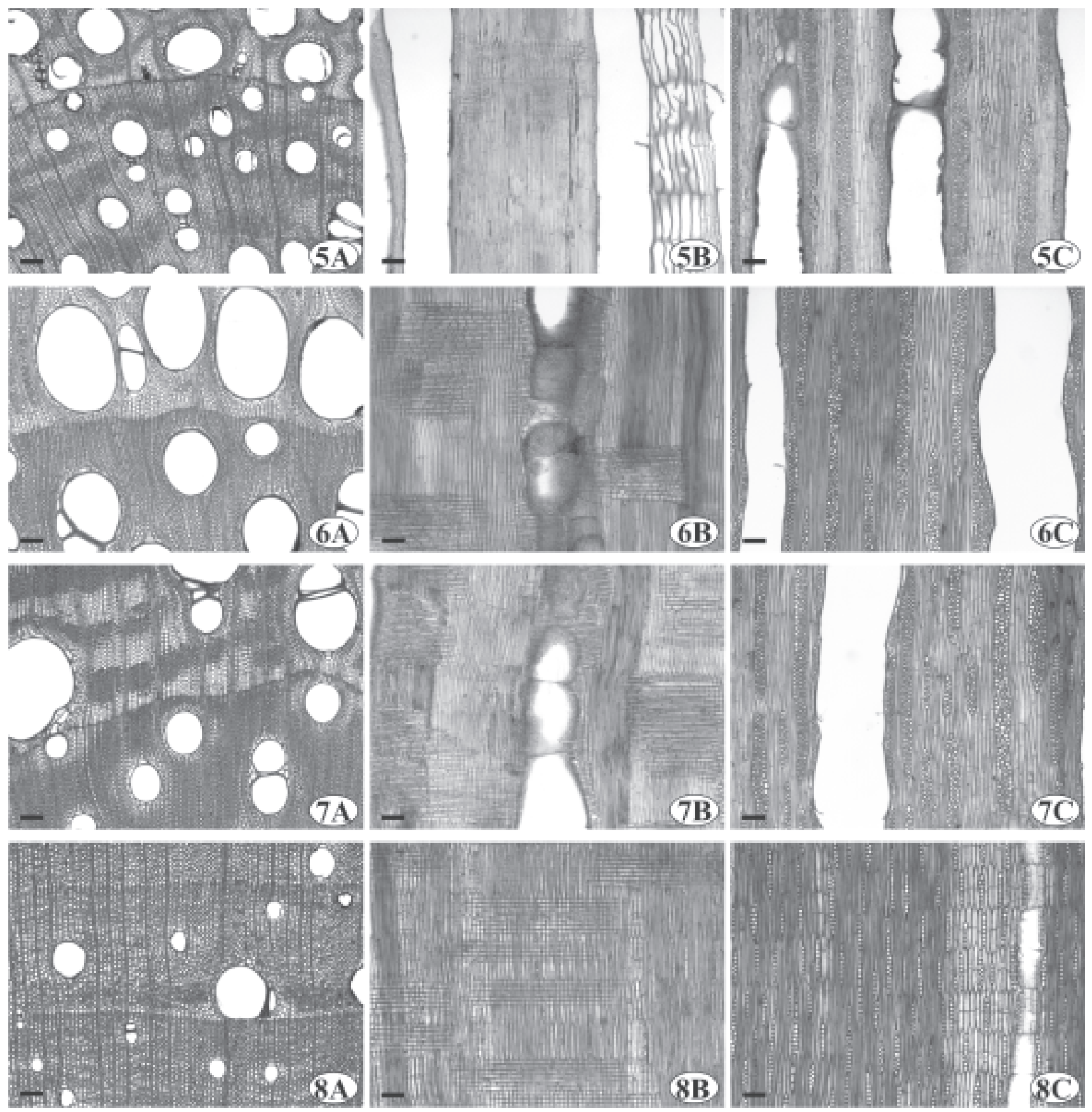

Figuras 5-8. Visão microscópica dos planos: transversal (A), radial (B) e tangencial (C). 5. Senegalia tenuifolia (L.) Willd. 6. Piptadenia adiantoides (Spreng.) J.F. Macbr. 7. Piptadenia micracantha Benth. 8. Dalbergia frutescens (Vell.) Britton var. frutescens. Barras $=$ $100 \mu \mathrm{m}$. 

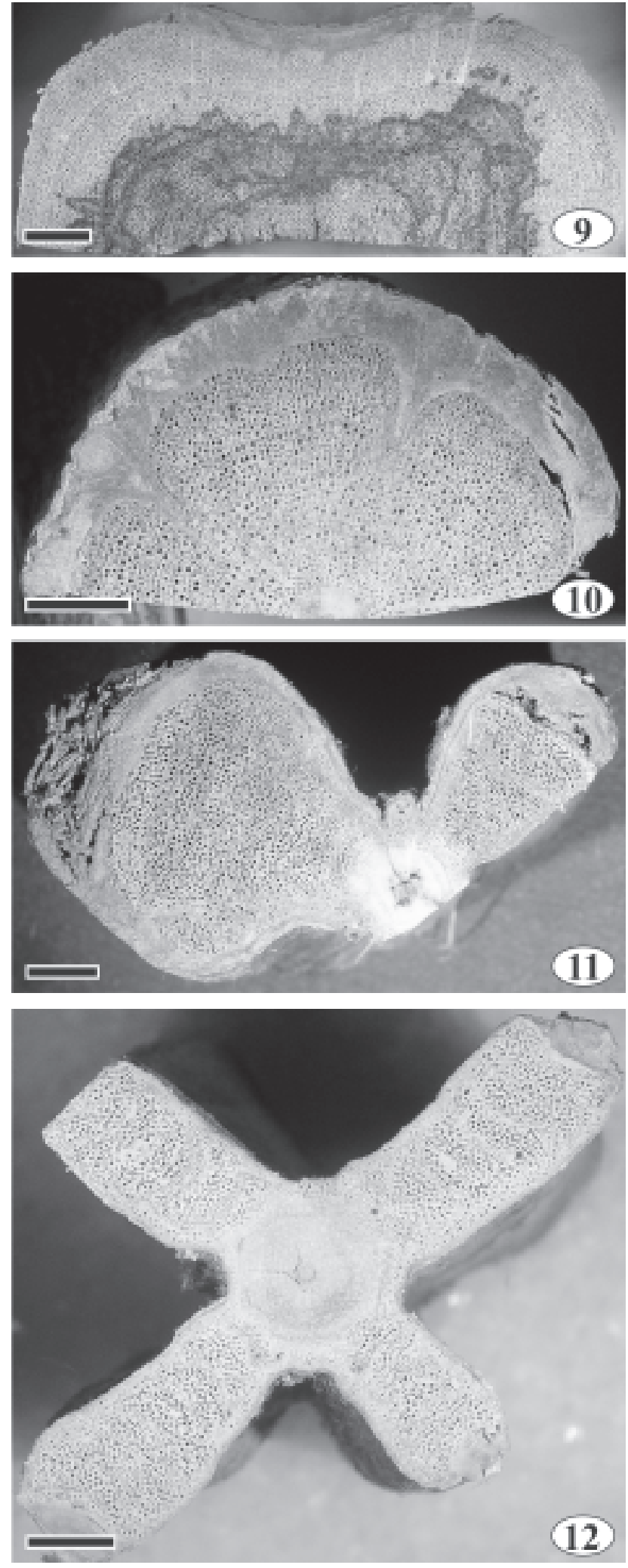

Figuras 9-12. Visão do plano transversal das espécies que apresentam variações cambiais. 9. Senegalia grandistipula (Benth.) Seigler \& Ebinger. 10. Senegalia lacerans (Benth.) Seigler \& Ebinger. 11. Senegalia martiusiana (Steud.) Seigler \& Ebinger. 12. Senegalia pedicellata (Benth.) Seigler \& Ebinger. Barras $=1 \mathrm{~cm}$. a maior freqüência de vasos por milímetro quadrado. Em $D$. frutescens os vasos são curtos, com menor média e variação, além disso, tem menor numero de vasos agrupados. Foi realizada a análise de distribuição amostral para o diâmetro dos vasos e constatou-se que todas as espécies apresentaram distribuição bimodal, exceto $D$. frutescens.

As fibras são longas em $S$. tenuifolia, com média de 1193,24 $\mu \mathrm{m}$. Essa espécie também se destaca pela elevada média e máximo de altura do raio em número de células e micrometros. Em antagonismo, D. frutescens apresenta raios baixos com uma pequena média, amplitude e variação. Senegalia tenuifolia, $P$. adiantoides, $P$. micracantha formam um grupo que difere das outras espécies por apresentar raios largos e altos. Dalbergia frutescens foi a espécie que apresentou maior frequiência de raios por milímetro linear. Essa espécie também apresentou maior porcentagem média de fibras e menor porcentagem média de vasos, quando comparadas com as outras espécies. Todas as espécies apresentaram alta porcentagem de vasos e parênquima axial, destacandose $S$. martiusiana pela elevada média de vasos representando aproximadamente $50 \%$ do tecido xilemático e $S$. pedicellata com média de $43 \%$ de parênquima axial. Senegalia tenuifolia, $P$. adiantoides, $P$. micracantha não apresentaram tão altas proporções de parênquima axial, mas apresentaram as mais elevadas de parênquima radial. Senegalia martiusiana e $S$. pedicellata apresentaram a menor quantidade relativa de fibras. Dalbergia frutescens apresentou um pequeno desvio padrão nas medidas de comprimento de vasos, altura do raio em número de células e em comprimento. Isso expressa numericamente a estratificação de raios, vasos e do parênquima axial que ocorre nesta espécie. O sumário das características quantitativas com a estatística descritiva pode ser observado na Tab. 1 .

Por meio da análise de fatores pelo método de componentes principais, foi constado que as características que mais influenciaram na distribuição espacial bidimensional das amostras foram: presença de variação cambial, freqüência de vasos, presença de fibras septadas, comprimento dos vasos, camadas de crescimento distintas, anel semiporoso, parênquima axial marginal, parênquima axial vasicêntrico, parênquima axial aliforme, diâmetro tangencial dos vasos, altura e largura dos raios em micrômetros, estratificação, parênquima axial difuso (Fig. 13); explicando 74\% da variação. A distribuição espacial bidimensional permite a distinção de 3 
grupos. Um com $P$. adiatoides, $P$. micracantha e $S$. tenuifolia, um segundo grupo com S. grandistipula, S. lacerans, S. martuisiana e S. pedicellata, e um grupo isolado somente com D. frutescens (Fig. 14).

$\mathrm{Na}$ análise de agrupamento as características qualitativas que se mostraram importantes foram: presença de variação cambial, o tipo de variação cambial, presença de fibras septadas, camadas de crescimento distintas, anel semi-poroso, parênquima axial marginal, parênquima axial vasicêntrico, parênquima axial paratraqueal escasso, parênquima axial aliforme, estratificação e parênquima axial difuso. Contudo, P. micracantha e S. tenuifolia não apresentam características qualitativas que permitam a distinção, permanecendo agrupadas (Fig. 15). Piptadenia adiantoides apresenta o parênquima axial paratraqueal escasso que a diferencia dessas duas espécies, mas por não ser uma característica observada em todas as amostras, não interfere no agrupamento. Observou-se pela análise da variância que a média do diâmetro dos vasos têm diferenças significativas entre as espécies S. tenuifolia, $P$. adiantoides e P. micracantha $(\mathrm{p}<0,01)$.

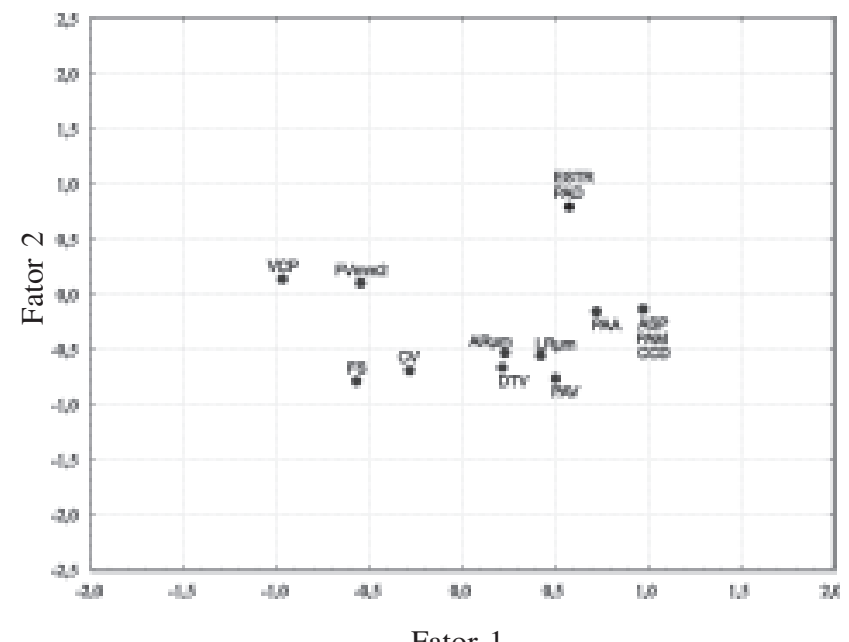

Fator 1

Figura 13. Análise de componentes principais. Representação gráfica bidimensional das variáveis que mais influenciaram na distibuição espacial das espécies quando descritas em dois fatores. $\mathrm{VCP}=$ variação cambial presente; $\mathrm{FVmm} 2$ = freqüência de vasos por milímetro quadrado; $\mathrm{FS}$ = fibras septadas; $\mathrm{CV}=$ comprimento dos vasos; $\mathrm{AR} \mu \mathrm{m}=$ altura dos raios em micrômetros; $\mathrm{LR} \mu \mathrm{m}=$ largura dos raios em micrômetros; DTV = diâmetro tangencial dos vasos; PAV = parênquima axial vasicêntrico; PAA = parênquima axial aliforme; $\mathrm{ASP}=$ anel semi-poroso; $\mathrm{PAM}=$ parênquima axial marginal; $\mathrm{CCD}=$ camadas de crescimento distintas; ESTR = estratificação; $\mathrm{PAD}=$ parênquima axial difuso.

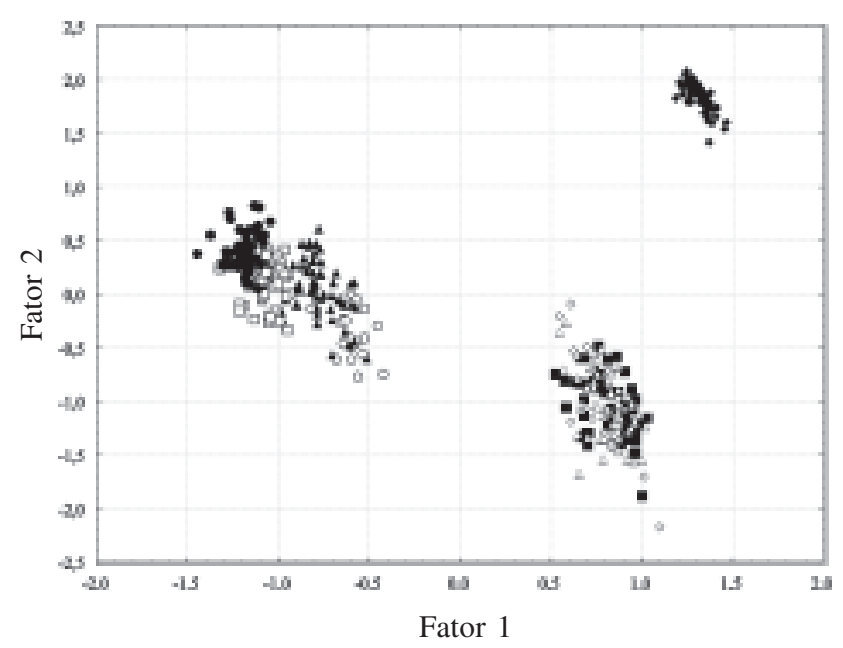

Figura 14 - Análise de componentes principais. Representação gráfica bidimensional das espécies quando descritas em dois fatores. $(\bigcirc=$ Senegalia grandistipula $; \boldsymbol{\Delta}=$ S. lacerans $; \square=$ S. martiusiana $;$

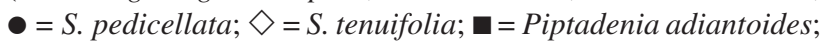
$\triangle=$ P. micrantha; $\bullet$ Dalbergia frutescens).

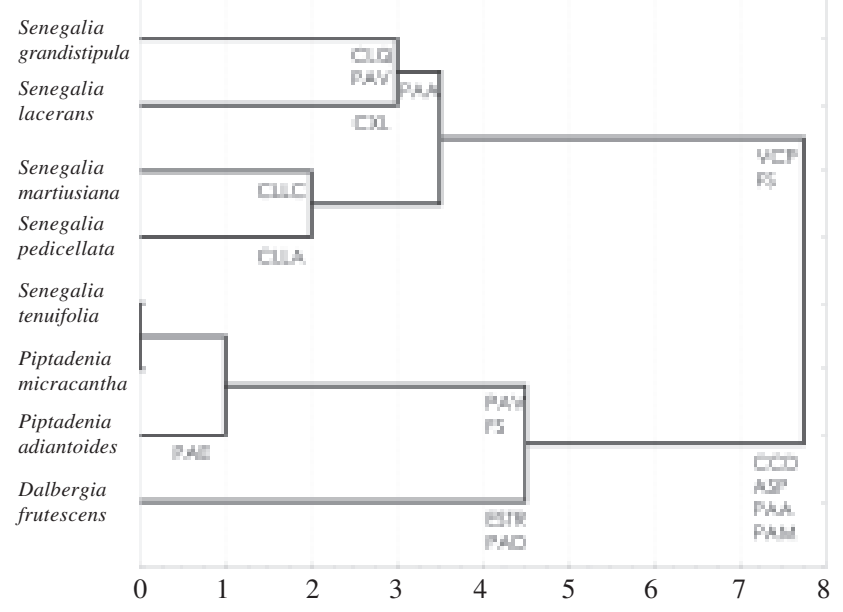

Figura 15. Análise de agrupamento. Dendrograma elaborado a partir de distâncias de Manhattan entre as 8 espécies estudadas (Manhattan distances, unweighted pair-group average). $\mathrm{VCP}=$ variação cambial presente; $\mathrm{FS}=$ fibras septadas; $\mathrm{CCD}=$ camadas de crescimento distintas; $\mathrm{ASP}=$ anel semi-poroso; $\mathrm{PAA}=$ parênquima axial aliforme; $\mathrm{PAM}=$ parênquima axial marginal; $\mathrm{PAV}=$ parênquima axial vasicêntrico; ESTR = estratificação; PAD = parênquima axial difuso; $\mathrm{PAE}=$ parênquima axial paratraqueal escasso; $\mathrm{CLQ}=$ caule lobado com aspecto quadrangular; $\mathrm{CXL}=$ caule com xilema fissurado; CLLC = caule lobado com lobos cilíndricos; CLLA = caule lobado lobos achatados.

\section{Discussão}

As espécies analisadas apresentam algumas características anatômicas do lenho atribuídas às lianas (Carlquist 1991; Bamber \& Ter Welle 1994). Quase todas as espécies têm vasos com dois diâmetros 
distintos (dimorfismo de vasos), todas as espécies têm grande diâmetro de vasos e quatro espécies do gênero Senegalia apresentam variações cambiais.

A ocorrência de vasos com grande diâmetro é freqüente nas lianas (Carlquist 1985). Carlquist (1975), comparando hábitos relata a média do diâmetro dos vasos de trepadeiras e lianas de $157 \mu \mathrm{m}$, comprimento de elementos de vaso com $334 \mu \mathrm{m}$ e grande área condutora (ou área de vasos por milímetro quadrado). Neste estudo, $P$. micracantha apresentou vasos com diâmetro médio de 300,36 $\mu$ m e máximo de 543,43 $\mu \mathrm{m}$. Senegalia pedicellata apresentou a segunda menor média de diâmetro com $131,19 \mu \mathrm{m}$, valor muito próximo ao citado por Carlquist (1975) para lianas, e considerado elevado.

O dimorfismo de vasos confere grande eficiência na condução, através dos vasos largos, e grande segurança, através dos vasos pequenos (Carlquist 2001). Contudo outros autores (Ewers et al. 1991) mencionam que a função dos vasos estreitos é incerta, mas pode ser importante para reserva e transporte de água no sentido radial e tangencial, na condução quando os vasos grandes estão embolizados e fazendo ligações hidráulicas entre partes da planta. Neste estudo foi constatado que ocorrem vasos de dois diâmetros distintos na maioria das espécies analisadas. Os vasos com diâmetro elevado são predominantemente solitários, enquanto os vasos de menor diâmetro encontram-se principalmente agrupados. O dimorfismo de vasos pode ser constatado através da análise de distribuição amostral. Carlquist (1985) relata que em plantas escandentes ocorrem vasos largos e estreitos concomitantemente, com relativamente poucos vasos com valores intermediários diferindo de uma distribuição normal. O termo "dimorfismo" não implica necessariamente que a distribuição amostral forme uma curva bimodal, mas sim qualquer derivação de uma curva de distribuição normal (Ewers \& Fisher 1989; Carquist 1991). A atenuação da curva de distribuição normal foi comum em dados analisados por Fisher \& Ewers (1989). Sete das espécies estudadas apresentaram distribuição bimodal e somente D. frutescens não apresentou. Neste estudo, D. frutescens não apresentou dimorfismo de vasos detectável pela análise de distribuição amostral. Contudo ocasionalmente vasos pequenos podem ser observados próximo a vasos grandes o que poderia levar outros autores a considerar como dimorfismo de vasos.

Na maioria das espécies em estudo os elementos de vaso são curtos com aproximadamente $400 \mu \mathrm{m}$ em média, exceto em $D$. frutescens onde foram observados elementos de vaso muito curtos, com média de 201,62 $\mu \mathrm{m}$. A espécie que apresentou os elementos de vaso mais longos foi $P$. micracantha, com média de 435,16 $\mu \mathrm{m}$. Estudos têm demonstrado que o comprimento dos elementos de vaso está mais relacionado com gêneros e espécies próximas do que com o hábito (Carlquist 1985), contudo podem ser verificadas diferenças quando comparadas lianas e árvores da mesma espécie. As Leguminosas apresentam elementos de vaso muito curtos a médios não ultrapassando $800 \mu \mathrm{m}$ (Baretta-Kuipers 1981; Wheeler \& Baas 1992), o que foi corroborado neste estudo.

A ocorrência de variações cambiais em lianas é bem conhecida. Contudo variação cambial na subfamília Mimosoideae é pouco relatada. Evans et al. (2006), que estudaram a anatomia do lenho de $70 \%$ dos gêneros da subfamília, constatou somente no gênero Entada tal característica. Neste estudo Senegalia grandistipula, S. martiusiana, S. pedicellata e $S$. lacerans apresentam um câmbio único, normal em produtos mas anormal na conformação, com formato lobado e não fragmentado no corte transversal nas três primeiras espécies citadas e com xilema fissurado em $S$. lacerans. A variação que confere o formato lobado já havia sido observada por Obaton (1960) em Acacia pennata e em outra espécie de Acacia por Netto (1863 apud Obaton 1960). Nestes tipos de variação o câmbio produz floema para o lado externo e xilema para o lado interno, contudo em algumas regiões o câmbio produz menos xilema que em outras (Carlquist 2001). No tipo caule lobado a variação é notada no lado externo do caule sem necessitar a secção transversal, contudo na espécie que apresenta xilema fissurado a variação é somente notada após ser seccionado transversalmente. $\mathrm{O}$ xilema fissurado é decorrente de uma pequena porção do câmbio que produz mais floema e menos xilema, tornando-se quase unidirecional (Carlquist 2001). Em todas as espécies com variação cambial analisadas geralmente ocorre a redução da produção de xilema em 4 regiões do caule.

Ao parênquima axial paratraqueal nas lianas é atribuída a função de recuperação do tecido vascular após injuria (Fisher \& Ewers 1989), aumento da flexibilidade (Putz \& Holbrook 1991) ou ainda a função de segurança e manutenção do sistema condutor, hidrolisando o amido a açúcar, movendo este para a água presente no vaso e gerando pressão osmótica que eleve a água a esta porção do vaso, evitando ou 
eliminando ar dos vasos largos (Carlquist 1985). Reserva de amido no parênquima adjacente aos vasos foi relatado por Carlquist (1985) em três gêneros de lianas da família Leguminosae (Hardenbergia, Mucuna, Wisteria). Nesse estudo foi observado que o amido não se concentrava apenas no parênquima adjacente aos vasos, mas estava presente em quase todas as células de parênquima axial. Observou-se também que a maioria das espécies não apresentava amido no parênquima radial. Apenas $D$. frutescens apresentou amido nos raios.

Nas espécies estudadas, o parênquima e os vasos compõe a maior parte do xilema secundário. Somente Senegalia martiusiana apresentou maior proporção de vasos do que parênquima. Em todas as espécies as fibras representam uma pequena parte do xilema secundário. Dalbergia frutescens apresentou mais parênquima (45\%) do que os outros tipos celulares, mas foi a única espécie a ser constituída por mais fibras $(40 \%)$ do que vasos (15\%). A presença de grande quantidade de parênquima nas lianas e a grande área condutora, que pode ser entendida como uma grande proporção de vasos, já havia sido citada por vários autores (Carquist 1985; Bamber \& Ter Welle 1994) e também foi evidenciada nesse estudo.

Todas as espécies desse estudo apresentaram fibras gelatinosas. As fibras gelatinosas geralmente são observadas nos caules de espécies arbóreas no lenho de tensão (Carlquist 2001) e também podem ser observadas nos caules de lianas, onde foi sugerido que podem aumentar a flexibilidade (Vieira 1994).

Além das características esperadas para o hábito muitas outras das características observadas devemse à história evolutiva da família Leguminosae, de suas subfamílias, gêneros e espécies. Diversas características anatômicas observadas no lenho, comuns a todas as espécies estudadas, correspondem às características atribuídas à família Leguminosae, que são: vasos solitários a múltiplos, placas de perfuração simples, pontoações intervasculares alternas guarnecidas; fibras com pontoações simples; raios homocelulares compostos por células procumbentes; parênquima axial paratraqueal, presença de cristais em células de parênquima subdivididas (Baretta-Kuipers 1981; Wheeler \& Baas 1992).

A maioria das Mimosoideae apresentam parênquima axial aliforme com diferentes graus de confluência. As células do parênquima axial podem ser fusiformes ou formar séries com mais de 8 células, sendo mais comum a ocorrência de séries de 2 a 4 células. A família Mimosoideae apresenta a anatomia do lenho muito homogênea e distinguível das outras duas subfamílias de Leguminosae (Evans et al. 2006). A estratificação é uma característica de pouca incidência na subfamília Mimosoideae e comum na subfamília Papilionoideae (Baretta-Kuipers 1981). Dalbergia frutescens, uma Papilionoideae, foi a única espécie deste estudo a apresentar essa característica. Todavia, fibras septadas são comuns na subfamília Mimosoideae (Baretta-Kuipers 1981) e foram observadas em todas as espécies desta subfamília neste estudo. Uma das funções atribuídas às fibras septadas, também chamadas de fibras vivas, é de reserva de amido (Carlquist 2001). Neste estudo foram realizados testes histoquímicos e foi confirmada a presença de amido no interior das fibras septadas. Em algumas fibras não septadas também se notou a presença de amido. Apesar de não terem sido quantificadas, constatou-se que as fibras septadas foram mais abundantes nas espécies do gênero Senegalia, e menos abundantes no gênero Piptadenia. A presença de fibras septadas também é referida como comum em lianas da família Bignoniaceae (Gasson \& Dobbins 1991). As características observadas nas espécies de Piptadenia e Senegalia se enquadram nas descrições realizadas por Evans et al. (2006) para o grupo Piptadenia da tribo Mimoseae e para o grupo Acacia da tribo Acaciaeae, respectivamente.

Bamber \& Ter Welle (1994) estudando a liana Acacia albizioides observaram diâmetro de vasos com média de $265 \mu \mathrm{m}, 39 \%$ de parênquima, 2-3 células de largura e $1 \mathrm{~mm}$ de altura dos raios, maior porcentagem de parênquima do que de fibras. No presente estudo, as espécies do gênero Senegalia, antes tratadas com Acacia, apresentaram menor diâmetro dos vasos do que o observado pelos referidos autores e a largura dos raios na maioria das espécies foi semelhante, exceto para $S$. tenuifolia que apresentou raios largos. Nenhuma espécie do gênero Senegalia, apresentou raios com altura média maior que $1 \mathrm{~mm}$. Em S. tenuifolia os raios chegam a atingir $3,26 \mathrm{~mm}$, mas a média é de $0,71 \mathrm{~mm}$. A porcentagem de parênquima foi maior que a observada pelos autores citados acima, com nenhuma espécie possuindo menos de $42 \%$ de parênquima.

A presença de cristais de oxalato de cálcio é uma característica conspícua em Leguminosae. No lenho de Papilionoideae e Mimosoideae os cristais são usualmente solitários, em câmaras compartimentalizadas (Zindler-Frank 1987). Todas as espécies estudadas apresentaram cristais prismáticos de oxalato de cálcio, em séries parenquimáticas com um cristal 
por subdivisão. As espécies com camadas de crescimento distintas apresentavam várias séries cristalíferas em seu limite, Segundo Evans et al. (2006), na família Mimosoideae os cristais são freqüentes no parênquima axial e comuns em fibras compartimentalizadas. Esses autores citam uma maior freqüência de cristais nos limites entre parênquima axial e fibras o que dificulta a identificação do tipo de célula os encerram (Evans et al. 2006). A mesma dificuldade foi encontrada no presente trabalho.

O parênquima axial pode auxiliar na distinção de gêneros (Baretta-Kuipers 1981), a exemplo de Dalbergia dos demais gêneros deste estudo. No entanto o padrão do parênquima axial não permitiu a diferenciação das espécies do gênero Senegalia e Piptadenia. O gênero Dalbergia apresenta uma combinação de características anatômicas do lenho que permite uma fácil distinção dos outros gêneros de Leguminosae (Wheeler \& Baas 1992). Isto também foi notado neste estudo, onde $D$. frutescens, diferiu das demais espécies por apresentar: parênquima apotraqueal difuso, difuso em agregados, estratificação e ausência de fibras septadas. Estas características correspondem às citadas em outros estudos (BarettaKuipers 1981; Gasson 2000).

Nas lianas da subfamília Mimosoideae ocorrentes na área de estudo, os caracteres morfológicos de folhas, algumas vezes não permitem a identificação das espécies, porém a anatomia do lenho pode auxiliar no reconhecimento das espécies. Evans et al. (2006) referem que as espécies de Mimosoideae, de um mesmo gênero geralmente apresentam um alto grau semelhança na anatomia do lenho. No presente trabalho tal aspecto foi observado em espécies de um mesmo gênero e de gêneros distintos. Senegalia tenuifolia, $P$. adiantoides e $P$. micracantha têm a anatomia do lenho muito semelhante. Piptadenia adiantoides apresenta parênquima axial paratraqueal escasso que a diferencia da demais, contudo não é uma característica evidente em todas as camadas de crescimento e amostras. As três espécies podem ser diferenciadas pelo diâmetro dos vasos, como foi constatado na análise de variância. Piptadenia micracantha apresenta os maiores vasos, enquanto $P$. adiantoides e $S$. tenuifolia apresentam vasos menores respectivamente. Senegalia tenuifolia também apresenta as fibras longas e raios altos quando comparada às outras duas espécies.

Foi constatado então que as espécies estudadas apresentam características anatômicas do lenho concordantes com características atribuídas às lianas e à família Leguminosae. Apesar de serem muito semelhantes, principalmente as espécies pertencentes à subfamília Mimosoideae, elas podem ser diferenciadas pela anatomia do lenho. Algumas mais facilmente, como as espécies com variação cambial e D. frutescens, e outras que necessitam de muita cautela e uma boa comparação para serem notadas as sutilezas das diferenças, como em $S$. tenuifolia, $P$. adiantoides e $P$. micracantha.

\section{Agradecimentos}

Agradecemos ao Instituto de Pesquisas Jardim Botânico do Rio de Janeiro - Programa Mata Atlântica e a CAPES (Coordenação de Aperfeiçoamento de Pessoal de Nível Superior), pelo auxílio financeiro; ao Parque Nacional do Itatiaia e ao Programa Mata Atlântica, pelo apoio logístico; à Dra. Cecília Gonçalves Costa, pela atenta revisão e sugestões no manuscrito.

\section{Referências bibliográficas}

Bamber, R.K. \& Ter Welle, B.J.H. 1994. Adaptative trends in the wood anatomy of lianas. In: M. Iqbal (ed.). 1994. Growth Patterns in Vascular Plants. Portland, Oregon, Dioscorides Press.

Baretta-Kuipers, T. 1981. Wood Anatomy of Leguminosae: its relevance to taxonomy. Pp. 677-705. In: R.M. Polhill \& P.H. Raven (eds.). Advances in legumes systematics 1. Kew, Royal Botanic Gardens.

Bukatsch, F. 1972. Bemerkungen zur doppelfärbung astrablau-safranin. Mikrokosmos 61: 33-36.

Carlquist, S. 1975. Ecological Strategies of Xylem Evolution. California, The University of California Press.

Carlquist, S. 1985. Observations on functional wood histology of vines and lianas: vessel dimorphism, tracheids, vasicentric tracheids, narrow vessels, and parenchyma. Aliso 11: 139-157.

Carlquist, S. 1991. Anatomy of vine and liana stems: a review and synthesis. Pp. 53-72. In: F.E. Putz \& H.A. Mooney (eds.). The Biology of Vines. Cambridge, United Kingdom, Cambridge University Press.

Carlquist, S. 2001. Comparative wood anatomy: systematic, ecological and evolutionary aspects of dicotyledon wood. $2^{\text {nd }}$ ed. Berlin, Springer-Verlag.

Ceccantini, G. 1997. Cortes de madeira em micrótomo de deslize. Pp. 125-127. In: J.E. Kraus \& M. Arduin. Manual básico de métodos em morfologia vegetal. Rio de Janeiro, Edur, Apêndice III.

Evans, J.A.; Gasson, P.E. \& Gwilym, P.L. 2006. Wood Anatomy of the Mimosoideae (Leguminosae). IAWA Journal Supplement 5: 1-118.

Ewers, F.W. \& Fisher, J.B, 1989. Variation in vessel length and diameter in stems of six tropical and subtropical lianas. American Journal of Botany 76: 1452-1459. 
Ewers, F.W. \& Fisher, J.B. 1991. Why vines have narrow stems: histological trends in Bauhinia (Fabaceae). Oecologia 88: 233-237.

Ewers, F.W.; Fisher, J.B. \& Fichtner, K. 1991. Water flux and xylem structure in vines. Pp. 127-160. In: F.E. Putz \& H.A. Mooney (eds.). The Biology of Vines. Cambridge, United Kingdom, Cambridge University Press.

Fisher, J.B. \& Ewers, F.W. 1989. Wound healing in stems of lianas after twisting and girdling injuries. Botanical Gazette 150: 251-265.

Gasson, P.2000. Does wood anatomy support tribal and generic classification in Papilionoid Leguminosae. Pp. 201-215. In: P.S. Herendeen \& A. Bruneau (eds.). Advances in Legume Systematics 9. Kew, Royal Botanic Gardens.

Gasson, P. \& Dobbins, D.R. 1991. Wood anatomy of the Bignoniaceae, with a comparison of trees and lianas. IAWA Bulletin 12: 389-417.

Gentry, A.H. 1991. The distribution and evolution of climbing plants. Pp. 3-50. In: F.E. Putz \& H.A. Mooney (eds.). The Biology of Vines. Cambridge, United Kingdom, Cambridge University Press.

Gerwing, J.J.; Schnitzer, S.A.; Burnham, R.J.; Bongers, F.; Chave, J.; Dewalt, S.J.; Ewango, C.E.N.; Foster, R.; Kenfack, D.; Martínez-Ramos, M.; Parren, M.; Parthasarathy, N.; Pérez-Salicrup, D.R.; Putz, F.E. \& Thomas, D.W. 2006. A Standard Protocol for Liana Censuses. Biotropica 38: 256-261.

Iawa Committee 1989. List of microscopic features of hardwood identification. IAWA Bulletin 10: 219-332.

Ibama 2006. Instituto Brasileiro do Meio Ambiente e dos Recursos Naturais Renováveis. Parque Nacional do Itatiaia. Publicado na internet. http://www.ibama.gov.br/ parna_itatiaia/index.php?id_menu=155.

Jane, F.W. 1956. The structure of wood. Londres, Adam \& Black.

Johansen, D.A. 1940. Plant microtechnique. New York, McGraw-Hill Book Co.

Manly, B.F.J. 1994. Multivariate statistical methods. $2^{\text {nd }}$ ed. London, Chapman \& Hall.
Obaton, M. 1960. Les lianes ligneuses à structure anormales des forêts dense d'Afrique occidentale. Annales des Sciences Naturelles, (Botanique) 12: 1-220.

Oliveira Filho, A.T. \& Fontes, M.A.L. 2000. Patterns of Floristic Differentiation among Atlantic Forests in Southeastern Brazil and the influence of Climate. Biotropica 32: 793-810.

Putz, F.E. \& Mooney, H.A. 1991. The Biology of Vines. Cambridge, United Kingdom, Cambridge University Press.

Putz, F.E. \& Holbrook, N.M. 1991. Biomechanical studies of vines. Pp. 73-98. In: F.E. Putz \& H.A. Mooney (eds.). The Biology of Vines. Cambridge, United Kingdom, Cambridge University Press.

Resende, A.A. \& Ranga, N.T. 2005. Lianas da Estação Ecológica do Nordeste Paulista, São José do Rio Preto / Mirassol, SP, Brasil. Acta Botanica Brasilica 19: 273-279.

Sass, J.E. 1958. Elements of botanical microtechnique. New York, London, Mc. Graw, Hill Bood Co.

Schnitzer, S.A. \& Bongers, F. 2002. The ecology of lianas and their role in forests. Trends in Ecology and Evolution 17: 223-230.

Segadas-Vianna, F. \& Dau, L. 1965. Ecology of the Itatiaia Range, Southeastern Brazil. Arquivos do Museu Nacional 53: 31-53.

Strasburger, E. 1924. Handbook of practical botany. New York, MacMillan Company.

Vieira, R.C. 1994. Estrutura do Caule de Bauhinia radiata Vell. em Diferentes Ambientes. Revista Brasileira de Biologia 54: 293-310.

Zinder-Frank, E. 1987. Calcium oxalate crystals in legumes. Pp. 279-316. In: C.H. Stirton (ed.). Advances in Legume Systematics 3. Kew, Royal Botanic Gardens.

Wheeler, E. \& Baas, P. 1992. Fossil wood of the Leguminosae: A case study in xylem evolution and ecological anatomy. Pp. 281-301. In: P.S. Herendeen \& D.L. Dilcher (eds.). Advances in Legume Systematics 4. Kew, Royal Botanic Gardens. 